\title{
ESTRUCTURAS DE ACOGIDA DE LOS MORISCOS EMIGRANTES DE ESPAÑA EN EL MÁGREB (SIGLOS XIII AL XVIII)
}

\author{
MÍKEL DE EPALZA
}

Catedrático de Estudios Árabes e Islámicos.

Universidad de Alicante.

\section{SITUACIÓN DEL TEMA}

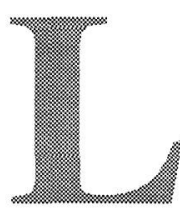

os movimientos migratorios en el Mediterráneo han sido continuos, a lo largo de la historia, e impulsados por los más variados motivos. La Antigüedad griega ha dejado una obra clásica, la Odisea, con un personaje que personifica al viajero por ese mar, Ulises, y una palabra que ha quedado en castellano para definir esos viajes: «una odisea» (nada parecido a esos viajes en avión del turismo actual, aunque sean en chárter $)^{1}$. Los árabes y musulmanes ${ }^{2}$ tienen también su viajero emblemático, Ibn-Batutta, que recorrió los tres continentes conocidos ${ }^{3}$, y una palabra clave, la rihla o «recorrido», que ha dado también el nombre a un importante género de literatura geográfica en árabe ${ }^{4}$.

1 Véase mi pequeño estudio sobre el paso de la noción árabe-islámica de «rizq» («ayuda divina» en los viajes) a la moderna de «riesgo» («peligro») a través del italiano medieval y de los seguros contra los riesgos marítimos en el Mediterráneo, en M. de Epalza, «Notas sobre la etimología árabe-islámica de «riesgo»», Sharq Al-Ándalus. Estudios Árabes, Alicante, 6, 1989, 185-192.

2 «Árabes» por la lengua, «musulmanes» por la religión, los «andalusíes» de Al-Ándalus [Península Ibérica musulmana] y los «magrebíes» del Mágreb o Magreb [Noroeste de África] tenían grupos específicos: lingüísticamente, los «hispanos» que hablaban una lengua derivada del latín, llamada actualmente «lengua mozárabe», y los «beréberes» o amazigh que hablaban -y hablan aún hoy en día- diversas formas del «beréber» o «bereber»; religiosamente, también coexistieron durante muchos siglos con los «musulmanes sunníes», generalmente dominantes y cada vez más mayoritarios, comunidades reconocidas de «judíos» y de «cristianos» [llamados actualmente «mozárabes»], con otros grupos musulmanes (fatimíes y otros movimientos chíes, jarichíes, bargawata, etc.). Ver para estas nociones, y para la realidad actual del Islam, M. de Epalza (dir.), L'Islam d'avui, de demà i de sempre, Barcelona, 1994.

3 Natural de Tánger (1304-1377), sus relatos de viaje fueron recogidos por el andalusí IbnChuzái de Granada y han sido traducidos al castellano: S. Fanjul; F. Arbós, Ibn Battûta. A través del Islam, Madrid, 1981. El más importante barco de las navieras libias lleva el nombre de Ibn Batuta, símbolo emblemático de los viajes árabes.

4 El mejor representante de este género es seguramente el escritor andalusí, de la región valen- 
El flujo actual de emigrantes laborales del Norte de África a Europa Occidental -tema específico en este volumen de la revista «Alternativas. Cuadernos de Trabajo Social», de la Universidad de Alicante- ha sido evocado como «el retorno de los moriscos» (Bernabé López García), en referencia a la expulsión general de los últimos musulmanes de la Península, que habían sido obligados a hacerse cristianos a principios del siglo XVI y fueron obligados a salir de España a principios del XVII, acabando instalándose en la sociedad del Norte de África la mayoría de los que consiguieron sobrevivir a la odisea de los viajes de la expulsión ${ }^{5}$.

En este pequeño estudio, se van a presentar las principales estructuras de acogida que tuvieron los musulmanes peninsulares en las sociedades musulmanas, especialmente en el Mágreb y con especial referencia a los moriscos expulsados de España a principios del siglo XVII $(1609-1614)^{6}$. Pero hay que saber situar este episodio de la historia de

ciana, Ibn-Chubair (1145-1217), cuya obra ha sido también traducida al castellano: F. Maíllo, Ibn Yubayr. A través del Oriente. El siglo XII ante los ojos. Rihla, Barcelona, 1988.

5 Hay que recordar el vocabulario histórico general para designar a los musulmanes peninsulares: «andalusíes» u originarios de Al-Ándalus, Hispania islamizada o la Península Ibérica bajo el poder político musulmán; «mudéjares», cuando viven en los reinos cristianos hispanos (Aragón, Castilla, Navarra, Portugal), en comunidades o «aljamas» reconocidas oficialmente como musulmanas; «moriscos», cuando esos mudéjares son obligados a convertirse al cristianismo, aunque la mayoría de ellos se mantuvieran fieles a su identidad islámica, secretamente, como cripto-musulmanes. Otros nombres medievales -como «agarenos», «ismaelitas», «sarracenos»-, que designan a los musulmanes en general, no son de uso actual. Tampoco «moro», por su sentido despectivo.

Geográficamente, el Mágreb o Magreb designa todo el occidente musulmán o Norte de África occidental: la UMA (Unión del Mágreb Árabe) reúne a los estados de Libia, Tunisia, Argelia, Marruecos y Mauritania. Todos sus habitantes pueden llamarse, por tanto, «magrebíes». Pero hay a veces cierta ambigüedad, en nuestros días, porque los marroquíes o «habitantes del Reino de Marruecos» (denominación en todas las lenguas europeas, que viene de su capital tradicional, Marraquesh) se llaman a sí mismos «magrebíes» (del nombre árabe actual de su país, El Mágreb o Reino Magrebí). La prensa va usando cada vez más «magrebí» para designar a los marroquíes (por ejemplo, «el paso de los magrebíes por España», en verano) dejando el término más tradicional de «marroquí» y creando equívocos con los demás magrebíes. Este equívoco es bastante consciente en muchos musulmanes de Ceuta y Melilla, «magrebíes» en castellano y «marroquíes» en árabe».

- Sobre los moriscos en general, ver las síntesis clásicas de A. Domínguez Ortiz - B. Vincent, Historia de los moriscos. Vida y tragedia de una minoría, Madrid, 1978, 1985, 1989, y M. de Epalza, Los moriscos antes y después de la expulsión, Madrid, 1992, 1994. Sobre la expulsión, últimas aportaciones científicas en M. de Epalza (dir), L'expulsió dels moriscos. Conseqüències en el món islàmic i en el món cristià, Barcelona, 1994 [43 ponencias y comunicaciones, en castellano, catalán, francés e inglés]. Para estar al día de las publicaciones científicas sobre mudéjares y moriscos, aportación bibliográfica en la revistaSharq Al-Ándalus. Estudios Árabes, de la Universidad de Alicante [desde vol. 1, 1984, actualmente con el 
las migraciones mediterráneas en el contexto de su época y, en particular, de las emigraciones hispánicas en la sociedad magrebí?

\section{ESTRUCTURAS DE ACOGIDA TRADICIONALES DE LOS ANDALUSÍES EN EL MÁGREB}

Sintetizando más de nueve siglos de relaciones entre Al-Ándalus y el Mágreb, «entre las dos orillas» ${ }^{8}$, como lo expresaban en árabe los escritores medievales (desde la llegada de los musulmanes a Hispania, en 711, a la expulsión final, en 1614), las estructuras tradicionales de acogida de los andalusíes en las sociedades magrebíes son bastante constantes. Serán la base -no la única, como se verá- de las estructuras de acogida de los moriscos, en la masiva inmigración que provocó la gran expulsión española del XVII.

\subsection{Infraestructuctura del deber islámico de la Peregrinación}

Lo primero que hay que decir es que la sociedad musulmana en general tiene tradicionalmente importantes infraestructuras de acogida para los viajeros. Es una sociedad de viajeros, por la obligación que tienen los musulmanes de realizar la Peregrinación a La Meca (Makka), al menos una vez en la vida, si tienen la posibilidad de hacerlo".

\subsection{Carácter urbano y cosmopolita de la religión islámica}

Por otra parte, la sociedad islámica, estructurada por la fe del Islam, es una sociedad urbana y comercial, que heredó de las sociedades ur-

Centro de Estudios Mudéjares con el subtítulo Estudios Mudéjares y Moriscos, desde el vol. 12, 1995], y en el boletín Aljamía [en colaboración con la Universidad de Oviedo, desde 1989], por los Dres. L.F. Bernabé Pons, M. de Epalza y F. Franco Sánchez, del área de Estudios Árabes e Islámicos, de la Universidad de Alicante.

7 Ver unas reflexiones sobre el tema en M. de Epalza, «Reflexiones sobre la insersión social de los españoles en el Mágreb a partir de la Baja Edad Media», Segundo Congreso Internacional de Estudios sobre las Culturas del Mediterráneo Occidental, Barcelona, 1978, 171-165 [reproducido como apéndice al final de este artículo]. Ver también mi participación en los dos volúmenes de Destierros aragoneses, Zaragoza, 1988, 217-227, ambos muy interesantes para nuestro tema: «Caracterización del exilio musulmán: la voz de mudéjares y moriscos».

8 Ver M. de Epalza, «Costas alicantinas y costas magrebíes: el espacio marítimo musulmán según Ios textos árabes», Sharq Al-Ándalus. Estudios Árabes, 3, 1986, 25-31; 4, 1987, 4548.

9 Ver ritual de las ceremonias en F. M. Pareja, Islamologia, Madrid, 1952-1954, tomo II, 538546; A. Machordoms Comín, Las Columnas del Islam, Madrid, 1979, 60-69; y en cualquier tratado sobre los ritos y preceptos islámicos. 
banas que le precedieron (especialmente las herederas a su vez de las civilizaciones romana y persa) una importante red viaria -que supieron conservar y desarrollar-de calzadas y caminos terrestres, de navegación marítima especializada en el cabotaje y de acogida de viajeros.

Las estructuras sociales de acogida de los foráneos estaban favorecidas también por la evolución de la sociedad musulmana hacia un cosmopolitismo nuevo. La religión musulmana, sin suprimir los lazos étnicos y hasta tribales de las sociedades precedentes, desarrolló unas sociedades cosmopolitas en las ciudades de su imperio -ya desde La Meca y Medina, y a pesar de las fragmentaciones políticas-, que favorecían la insersión de los extranjeros ${ }^{10}$.

\subsection{Los andalusíes, viajeros al Mágreb y Oriente}

Los andalusíes, desde sus inicios, viajaron mucho a Oriente, por mar directamente o visitando diversas regiones magrebíes (los musulmanes, porque tenían muchas veces raíces familiares en el Mágreb o en el Máshreq u Oriente árabe, o por intereses científicos y comerciales en las principales ciudades magrebíes, como Kairawán, Túnez, Bona/ Annaba, Bujía/Bidjaia, Tremecén/Tlemcén, Fez, Marráquesh...; los judíos, por sus relaciones con sus correligionarios magrebíes u orientales; y hasta los nobles visigodos cristianos del momento de la conquista, que visitaron a los califas de Damasco por diversas razones políticas, como el obispo Oppas, la princesa Sara, el noble Teodomiro, etc.).

A la vuelta de la peregrinación, muchos andalusíes se quedaban en las diversas ciudades del Máshreq o del Mágreb, formando colonias de andalusíes que acogían con especial hospitalidad a los nuevos viajeros de Al-Ándalus. Estas colonias están perfectamente documentadas en ciudades como Alejandría, El Cairo, La Meca, Medina, Bagdad, Damasco, Jerusalén y las ya mencionadas ciudades magrebíes.

\subsection{Emigraciones por conquistas hispano-cristianas (ss.XII-XV)}

Todas estas infraestructuras medievales fueron muy importantes para acoger a los andalusíes cuando los avances de las conquistas cristianas fueron reduciendo los territorios de dominio político musulmán.

Esas conquistas fueron desplazando poblaciones musulmanas hacia el Mágreb, especialmente con la ocupación cristiana de ciudades, que dejaban sin poder a las clases dirigentes árabes. Las caídas de Toledo

10 Ver, por ejemplo, magnífica visión general de A. Hourani, Historia de los pueblos árabes, Barcelona, 1992, o los estudios más especializados reunidos por J.L. Corral Lafuente; M. de Epalza, La Ciudad Islámica, Zaragoza, 1991. 
(1085), de Zaragoza (1118) y de las últimas ciudades del Valle del Ebro, Tortosa y Lleida (1149), etc., iniciaron un fenómeno de emigración de poblaciones, tanto hacia el sur de Al-Ándalus como hacia el vecino Mágreb, atraídos especialmente por la nueva sede del poder, Marrakech, capital -desde mediados del siglo XI- de las dinastías almorávide y almohade, que gobernaban lo que quedaba del territorio musulmán de Al-Ándalus ${ }^{11}$.

Cuando las grandes conquisas cristianas del siglo XIII -Baleares, Valencia, Murcia, Valle del Guadalquivir, Algarve portugués-, la emigración andalusí ya fue masiva, tanto al reino de Granada de la dinastía nazarí como, sobre todo, a los reinos magrebíes post-almohades de Marrakesh, Fez, Tremecén y Túnez. Los grandes funcionarios de esos reinos post-almohades eran generalmente de origen andalusí y pesaron mucho en la transmisión de los modelos culturales andalusíes en las sociedades magrebíes $^{12}$. A lo largo de los siglos XIII al XV (hasta la caída del reino de Granada, 1482-1492) el goteo de emigrantes andalusíes hacia el Mágreb, tanto del reino nazarí musulmán de Granada como de musulmanes mudéjares de los reinos hispanos cristianos, fue constante, aprovechando precisamente las anteriormente citadas infraestructuras de acogida ${ }^{13}$.

La emigración que siguió a la guerra de conquista de Granada sólo nos es conocida parcialmente, por la escasez de las fuentes y por la falta de estudios globales científicos ${ }^{14}$. A pesar de la importante masa

"Ver magnífica novela que retrata bien el inicio de estos éxodos, del Profesor de Historia Medieval de la Universidad de Zaragoza Dr. José Luis Corral Lafuente, El Salón Dorado, Barcelona, EDHASA, 1996.

12 Ver el caso emblemático del valenciano Ibn-Al-Abbar, que intervino en la rendición de la ciudad de Valencia (1238), de cuyo soberano era ministro, y que pasó a tener varios cargos en la corte de Túnez, donde acabó condenado a muerte. Estudios variados y muy completos en M. de Epalza; J. Huguet (coords.), Ibn Al-Abbar. Polític $i$ escriptor àrab valencià (11991260), Valencia, 1990 [17 estudios, en castellano, en catalán-valenciano y en francés]. Ver también M. de Epalza, «Las influencias de las culturas de Al-Ándalus en el Mágreb», en M.A. Roque (ed.), Las culturas del Magreb, Madrid, 1994, $75-89$ (trad. catalana, en Les cultures del Magreb, Barcelona, 1994, 63-73).

13 Ver dos curiosos relatos autobiográficos de viajeros peregrinos, pero también con un magrebí instalado en Aragón y un alfaquí mudéjar que prepara su emigración y acaba instalándose en el reino de Túnez, todos pasando por Mallorca y Tortosa, en M. de Epalza, «Dos textos moriscos bilingües (árabe y castellano) de viajes a Oriente (1395 y 1407-1412)», HespérisTamuda, Rabat, XX-XXI, 1982-1983, 25-112. Para último período de los mudéjares de Valencia, antes de su obligada conversión de 1526, ver E. Salvador, «Sobre la emigración mudéjar a Berbería. El tránsito legal a través del puerto de Valencia durante el primer cuarto del siglo XVI», Estudis, Valencia, 4, 1975, 39-68, y M.D. Meyerson, Els musulmans de València en l'època de Ferran i Isabel. Entre la coexistència i la croada, Valencia, 1994.

14 Ver los clásicos estudios de M.A. Ladero Quesada y J.E. López de Coca, renovados con ocasión de la conmemoración del V Centenario por obras colectivas que han dirigido estos 
de emigrantes, frenada por disposiciones de Reyes Católicos (privilegios a nobles granadinos, conversiones forzosas al cristianismo, etc.), las estructuras de insersión en el Mágreb, heredadas de siglos pasados, debieron funcionar, porque pocos problemas de adaptación quedan registrados en las fuentes históricas.

\subsection{Emigraciones peninsulares a Marruecos y Argelia (s.XVI)}

\section{A. De la obligación, o no, de emigrar a territorio musulmán ${ }^{15}$}

La obligación de no permanecer en una sociedad no-musulmana y de emigrar de ella hacia territorios donde reina la ley islámica es un tema de cierta importancia en el Islam, que da prioridad al vivir en una sociedad islámica, como la que creó el profeta Mahoma/Muhámmad en Medina, frente a otras posibilidades como las de las comunidades que él mismo envió desde La Meca, antes de su hégira a Medina.

La situación de musulmanes «emigrantes» a sociedades no-musulmanas se dio pronto en el Islam, por los numerosos viajeros que hacían comercio o estaban de embajadas muy oficiales -o las dos cosas a la vez-fuera de territorios gobernados por autoridades musulmanas. Cómo vivir en esas sociedades, si se mantienen en ellas los musulmanes y sus comunidades, ha dado lugar a una producción teológica islámica muy particular, con una doble tendencia: la más teórica y rigorista, que defiende la absoluta obligación de emigrar a tierras de musulmanes, y la más realista y permisiva, que se centra en las formas de vivir y convivir en sociedades gobernadas por no-musulmanes ${ }^{16}$.

Este tema fue particularmente importante en el Occidente musulmán, a medida que avanzaban las conquistas cristianas en el Mediterráneo occidental (Sicilia, Hispania). El jurista siciliano Al-Mazari, refugiado en Túnez tras la conquista cristiana de la isla (s.XI), ha deja-

dos catedráticos de Historia Medieval, de las Universidades Complutense y de Málaga, respectivamente.

15 Visiones generales de esa problemática de siglos y de la actualidad, en M.I. Fierro, «La emigración en el Islam: Conceptos antiguos, nuevos problemas», Awrâq, Madrid, 12, 1991, 11 41; K. Abou al-Fadl, «Islamic law and Muslim minorities: the juristic discourse on Muslim minorities from the second/eight to the eleventh/seventeenth centuries», Islamic Law and Society, Leiden, 1, 1994, 141-187; A. Carmona, «Los nuevos mudéjares: la shari'a y los musulmanes en sociedades no-islámicas», en M. Abumálham (ed.), Comunidades islámicas en Europa, Madrid, 1995, 49-59.

16 Ver mi conferencia innaugural del I Coloquio «La Voz de Mudéjares y Moriscos», Universidad de Alicante (marzo 1995): M. de Epalza, «La voz oficial de los musulmanes hispanos, mudéjares y moriscos, a sus autoridades cristianas: cuatro documentos, en árabe, en castellano y en catalán-valenciano», Sharq Al-Ándalus..., 12, 1995, en prensa. 
do uno de los textos más antiguos y razonados sobre el tema ${ }^{17}$. Otros textos declarativos (fatwas) se habían dado tras la ocupación cristiana de la mayor parte de los territorios de Al-Ándalus, a mediados del siglo XIII ${ }^{18}$. Pero fue la conquista cristiana de Granada y las sucesivas obligaciones de convertirse al cristianismo de los musulmanes «mudéjares» de los reinos hispanos (Portugal, 1497; Granada, 1500; Corona de Castilla, 1502; Navarra, después de 1512; Corona de Aragón, 1526) lo que iba a agudizar la tensión entre las dos tendencias ${ }^{19}$.

Los historiadores modernos han dilucidado que estas disputas teológicas islámicas venían muy condicionadas por posturas políticas: los partidarios de la emigración obligatoria miraban el reforzamiento del Islam en los estados musulmanes del Mágreb que acogerían a esos futuros soldados, mientras que los partidarios de permanecer en las sociedades hispanas miraban las posibilidades de formar unas comunidades de musulmanes también hispanos, germen de conversiones y de futuras conquistas del poder islámico en España.

Tema político fundamental tenía que ser precisamente la capacidad de estructuras de acogida en el Mágreb para esos musulmanes de las sociedades hispanas, en el siglo XVI, como se puede ver en dos ejemplos bien documentados, en Marruecos y en Argelia.

\section{B. La reconstrucción militar de Tetuán por los granadinos de Al- Mándari}

Una de las más importantes consecuencias de la caída de Granada, para la sociedad magrebí, fue la reconstrucción de la ciudad de Tetuán, por el dirigente granadino Al-Mándari, que supo atraer a muchos de sus compatriotas, emigrantes del ocupado Reino nazarí de Granada ${ }^{20}$.

17 Ver A.M. Turki, «Consultation juridique d'Al-Imâm Al-Mazârî sur le cas des musulmans vivant en Sicile sous l'autorité des Normands», Mélanges de l'Université Saint-Joseph, Beirut, L, 1984, 691-704, y «Pour ou contre la légalité du séjour des musulmans en territoire reconquis par les chrétiens: Justification doctrinale et réalité historique», Religiongespräche im Mittelalter (B. Lewis - F. Niewóhner edits.), Wiesbaden, 1992, 305-323, confirmado -en la práctica- en el estudio de $\mathrm{H}$. Bresc, «Pantelleria entre l'Islam et la Chrétienté», Les Cahiers de Tunisie, Túnez, XIX/75-76, 1971, 105-128. Reciente edición completa de las fatwas de Al-Mazari, por el profesor T. Al-Ma`mûrî, Fatâwâ...al-Mazârî́, Túnez, 1994.

18 Ver H. Bouzineb, «Respuestas de jurisconsultos maghrebíes en torno a la inmigración de musulmanes hispánicos», Hespéris-Tamuda, Rabat, 26-27, 1988-1989, 53-66; P.S. Van Koningsveld; G.A. Wiegers, «The Islamic statute of the Mudejars in the light of a new source», Al-Qantara, Madrid, XVII/1, 1996, 19-58.

19 Ver L. Sabbagh, «La religion des Moriscos entre deux fatwas», en L. Cardaillac; B. Vincent; P. Dedieu (editores), Les Morisques et temps, París, 1983, 45-56, y trabajos anteriormente citados sobre este tema.

20 Ver G. Gozálbes Busto, Al-Mandari, El Granadino, fundador de Tetuán, Granada, 1988, 1996. 
Tetuán era -y sigue siendo- la puerta de la región montañosa del Rif, que tiene al sur, y domina la llanura costera que tiene al norte, con la desembocadura del río Martil y finalmente la península de Ceuta, frente a las costas hispánicas. Por su situación estratégica, había sido víctima de una expedición cristiana, en 1437, que la arrasó, mientras que su vecina Ceuta era conquistada por los portugueses (1415) y pasaría mucho más tarde a los españoles $(1640)^{21}$.

La labor de Al-Mándari consistió precisamente en crear una estructura de acogida, civil y militar, en el Mágreb. Construyó -o reconstruyó- una ciudad, con todas sus estructuras urbanas islámicas, para el establecimiento de una población musulmana inmigrante. Pero también reforzó con esos inmigrantes las estructuras militares defensivas de una sociedad magrebí muy seriamente amenazada por el fuerte poder expansivo de los reinos hispanos, en el Atlántico y en el Mediterráneo desde Melilla a Trípoli, en menos de quince años ${ }^{22}$.

León El Africano, contemporáneo y compatriota de Al-Mándari, narra brevemente su gesta, con detalles que subrayan su acción de acogida e integración de musulmanes de Al-Ándalus en el Mágreb, en sus aspectos militares y civiles ${ }^{23}$ :

«...Obtuvo autorización para restablecer el gobierno de la ciudad y beneficiarse de él. Reconstruyó toda las murallas de Tetuán, construyendo una fortaleza muy sólida, y ciñó de fosos es a fortaleza, así como la muralla de la ciudad. Seguidamente guerreó sin parar con los portugueses. A menudo causó mucho mal a Ceuta, Alcazarseguer y Tánger. Tenía, en efecto, permanentemente consigo trescientos jinetes, todos granadinos y la flor de Granada...Ese hombre fue extremadamente generoso, al punto de recibir a todo extranjero que pasaba por la ciudad...».

De este y otros ejemplos puede deducirse que la estructura de la sociedad magrebí para acoger a los inmigrantes musulmanes de la Península Ibérica, en esa época, era una estructura urbana con sus ciudades cosmopolitas, y no zonas rurales más o menos montañosas del Mágreb medio (actual Argelia) o del Mágreb extremo (Marruecos) ${ }^{24}$.

21 Ver una excelente y reciente presentación general de la historia de Tetuán, por J.L. Miège; M. Benaboud; N. Erzini, Tétouan. Ville andalouse marocaine, París, 1996, y A. Djbilou, Tánger, puerta de Africa. Antología de textos literarios hispánicos, 1860-1960, Madrid, 1989. Sobre la Ceuta musulmana y sus restos arqueológicos, hasta nuestros días, excelente y también reciente estudio de C. Gozálbes Cravioto, El urbanismo religioso y cultural de Ceuta en la Edad Media, Ceuta, 1995.

22 Ver resumen de la historia de estas ocupaciones, con el catálogo y principales reproducciones hispánicas conservadas de esas ciudades, en M. de Epalza; J.B. Vilar, Planos y mapas hispánicos de Argelia (siglos XVI-XVIII), Madrid, 1988.

23 Traducción en G. Gozábes Busto, o.c., 26-27.

24 Ver M. de Epalza, Los moriscos, antes y después..., pp. 137-258. 
Y con expresa o tácita intención de reforzar las estructuras militares de los poderes políticos de la zona, tanto para su política interior como exterior.

\section{Andalusies en los ejércitos marroquies}

Dos hechos muy conocidos de la política militar marroquí a lo largo del siglo XVI y principios del XVII muestran la importancia de la estructura militar al servicio de los soberanos musulmanes en el fenómeno de insersión de los musulmanes mudéjares y moriscos inmigrantes de España, en el vecino Mágreb.

El primero es la participación de un cuerpo de ejército, compuesto por soldados moriscos y dirigidos por su jefe el almeriense Pachá Jáudar, en la expedición marroquí que envió el soberano Áhmad Al-Mansur Adh-Dháhabi a conquistar Tumbuctú y el cauce septentrional del río Níger. Esta expedición ha sido interpretada no sólo como una operación comercial marroquí para controlar el comercio de la sal, del oro y de otros productos subsaharianos, sino también para alejar de la corte marroquí a cuerpos de ejército poderosos, de origen extranjero y sospechosos de intervenir en las luchas políticas marroquíes. La ventaja de su fidelidad al soberano, por su origen extranjero, para dominar a la población marroquí y sus grupos, podía convertirse en inconveniente si pretendían intervenir en la propia política de los dirigentes marroquíes, inclinándose a favor de uno u otro bando de la corte ${ }^{25}$.

Precisamente unas décadas más tarde, justo antes de la gran expulsión de los moriscos de España de 1609-1614, la acción o defección del cuerpo de ejército de los andalusíes provocó el resultado negativo de la batalla llamada «de los Tres Reyes», que hundió al imperio marroquí en el caos y la anarquía, durante más de treinta años.

\section{Inmigrantes andalusíes en el nacimiento y poderío de Argel}

Argelia -el estado, provincia o regencia de Argel, como fue llamada- sintetiza, de otra forma, esos mismos elementos de estructura de acogida de los inmigrantes musulmanes de España, que se han detectado en la sociedad de Marruecos, antes de la gran expulsión final del siglo XVII.

25 En la abundante bibliografía sobre la expedición, ver M. García-Arenal, «Los andalusíes en el ejército Sa`adî: un intento de golpe de estado contra Ahmad Al-Mansûr Al.Dhanabî (1578)», Al-Qantara, Madrid, V, 1984, I. Diadié Haïdara, El bajá Yawdar y la conquista saadi del Songhay (1591 - 1569), Almeria, 1993, e interpretación global de la política de esos moriscos o andalusíes en M. Epalza, Los moriscos antes y después..., pp. 294-295. 
Argel -«Los Islotes», en lengua árabe, o «El Peñón de Argel», como se le llamaba en castellano- era una población insignificante, al pie de unas colinas junto al mar, y se transformó en magnífico puerto militar protegido por los islotes que tenía delante, en la primera década del siglo XVI. Los hermanos Barbarroja, artífices de esta transformación, eran extranjeros a la región y entregaron en 1517 el fruto de su trabajo -la ciudad y los territorios que habían conquistado, hasta las fronteras marroquíes- a otros extranjeros, los turcos del Imperio Otomano, que desde su capital Estanbul dominaban ya Anatolia, el Oriente árabe y gran parte de los Balkanes. Era la mejor forma de atraer a los otomanos hacia el Mediterráneo occidental, para que defendieran el Mágreb islámico de las ocupaciones hispánicas ya mencionadas. Así nació el espacio político argelino moderno, a principios del siglo XVI, como ciudad-estado marítimo y con un hinterland montañoso controlado por vías de comunicación de antiplanicies y de salidas al mar por unos pocos puertos (Bona, Chichel, Bujía, Cherchel, Tenés, Mostaganem, Honéin, etc.).

La creación de Argel corresponde, por tanto, al período de la conversión forzada de los musulmanes mudéjares hispanos en moriscos ya bastante perseguidos, religiosamente y en sus hábitos y costumbres -especialmente los granadinos-. La creación de esa gran ciudad cosmopolita, que atraía a toda clase de mediterráneos con esperanza de futuro -beréberes del interior, europeos convertidos al Islam, orientales de diverso origen y musulmanes hispanos- ofrecía a la emigración morisca unas estructuras sociales muy apropiadas para acogerlos.

No pueden describirse aquí todos los elementos de esas estructuras sociales. Pero están muy bien documentados unos cuerpos de ejército andalusíes -ya en la tercera década del XVI-, y moriscos de las costas valencianas instalados en el puerto de Cherchel vecino de Argel y haciendo naves para las autoridades otomanas, así como toda clase de artesanos que contribuyen a la prosperidad de la capital (en la contrucción, en las nuevas conducciones de agua, en el comercio y en todo lo relativo a las artes de navegación). También puede presuponerse el inicio de la agricultura alimentaria y de la arboricultura de los andalusíes, muy bien documentadas con los poblados moriscos posteriores a la gran expulsión, en el Valle de la Mitidja que rodea a las colinas costeras de Argel ${ }^{26}$.

El paralelismo con Marruecos es evidente: ciudad nueva como Tetuán, cuerpos de ejército terrestre y marítimo al servicio de las autoridades políticas musulmanas -aquí, nuevas; en Marruecos, más tra-

26 Ver M. de Epalza, Los moriscos antes y después..., pp. 205-259, y N. Saidouni, «Les Morisques dans la province d'Alger «Dar es-Soltan» pendant les XVIe et XVIle siècles», en M. de Epalza (coord.), L'exili dels moriscos..., 140-146. 
dicionales-y, globalmente, unas estructuras urbanas cosmopolitas muy flexibles, donde los musulmanes hispanos no desentonaban y donde podían insertarse con cierta facilidad los emigrantes musulmanes españoles, tanto moriscos como «cristianos viejos» recién convertidos al islam, en búsqueda de nueva vida en ese «ultramar» tan cercano.

\section{ESTRUCTURAS DE ACOGIDA, CUANDO LA GRAN INMI- GRACIÓN FINAL}

\subsection{Rechazo inicial de la sociedad magrebi hacia los moriscos}

La gran expulsión fue decidida y organizada con tanta rapidez como secreto. No se negoció el punto de destino con los países de acogida. Lo principal era su destierro o eliminación de los territorios españoles ${ }^{27}$.

De ahí que la primera etapa de las expulsiones (1609) fue una chapuza oficial que degeneró en una catástrofe para los emigrantes expulsados, los valencianos. Tenían que dirigirse a los puertos magrebíes de Orán-Mazalquivir, ocupados por España desde 1505, y desde esas ciudades amuralladas ser expulsados hacia los territorios circunvecinos, ocupados por tribus seminómadas sedentarizadas y políticamente dependientes del acuartelamiento turco de Mostaganem (a unos 50 kilómetros, al este), de la ciudad de Tremecén (Tilimsán) (a unos 150, al sur) y de la capital de la provincia, vilayet o regencia de Argel (a más de 500 kms., al este).

Apenas desembarcados, eran echados a territorio argelino, ya que ni la estrecha península del fuerte de Mazalquivir, ni la fortaleza de Orán podían estratégicamente albergar esas multitudes, ni tampoco alimentarlas. Entonces, las poblaciones rurales, que veían invadidas sus tierras por esos extranjeros con los que no tenían ni pacto, ni afinidad lingüística, ni cultural y ni siquiera vestimentaria, empezaron a defenderse y saquearles despiadadamente. No se había previsto, ni por parte española, ni por parte magrebí, la más elemental estructura de acogida de los emigrantes forzosos españoles.

Alertadas las autoridades musulmanas, tanto las de Argel como las del vecino reino de Marruecos (a unos $200 \mathrm{kms}$. de Orán, hacia el oeste), enviaron tropas para defender a los moriscos, castigar a los saqueadores y encaminar a los que habían logrado salvarse hacia las ciudades argelinas y marroquíes, respectivamente.

La estructura fundamental de acogida seguía siendo, como en el pasado, las ciudades tradicionales de Marruecos y las cosmopolitas de

27 Ver, para este proceso de expulsión H. Lapeyre, Géographie de l'Espagne morisque, París, 1959 [traducción española, sin índices, Valencia, 1986]; M. de Epalza, Los moriscos antes..., pp. 119-129 y M. de Epalza (coord.), L'exili dels moriscos..., así como sus fuentes. 
Argelia y el resto del Imperio Otomano, con sus capacidades comerciales y artesanales, sus alrededores agropecuarios y sus estructuras militares, todas ellas necesitadas y favorecedoras de mano de obra, especialmente la mano de obra especializada de muchos moriscos de la rica sociedad española.

Pero la mala acogida inicial, que tardó meses en corregirse (y fue jaleada en España, por cristianos partidarios de la expulsión, como un castigo divino a los musulmanes aferrados a su fe islámica), provocó fuertes reacciones en España, donde el proceso de expulsión seguía realizándose con un ritmo acelerado, cuyas características eran mortales para los moriscos: eran transportados a los puertos por militares o por sus señores feudales, que les esquilmaban; se embarcaban para Orán-Mazalquivir en naves militares, donde algunos (y algunas) eran reducidos a escavitud por los oficiales, o en naves civiles auxiliares, venidas de todo el Mediterráneo europeo atraídas por el negocio, jugoso si los moriscos más pudientes les pagaban para ser llevados a Argel $\mathrm{u}$ otras ciudades musulmanas (y luego eran desembarcados en la playa magrebí más cercana, como está documentado, o echados al mar, después de despojarles).

Esta circunstancia provocó rebeliones en las montañas valencianas, de moriscos que no querían emigrar en esas condiciones de peligrosidad, rebeliones que fueron aplastadas militarmente.

Pero, por otra parte, personalidades cristianas, eclesiásticas y laicas, se interesaban por la salvación del alma de los niños moriscos, abocados irremediablemente a ser musulmanes si emigraban a territorios islámicos. Pretendían, por tanto, que se les arrancara a sus padres expulsados y se confiara su educación a piadosos cristianos de cuya domesticidad formarían parte. Ante la resistencia natural de los padres y madres musulmanes, hubo de idearse una fórmula intermedia: expulsar a los moriscos a territorios cristianos europeos, donde podrían educar a sus hijos en la fe cristiana con tal de que no se los quitaran (fuentes españolas narran los gritos desgarradores de las madres, al embarcarse sin sus hijos en el puerto de Sevilla, por ejemplo).

\subsection{Expulsión por Europa: inserción y paso}

Las razones, someramente expuestas, que hacían inviables las emigraciones por Orán y otras plazas españolas en la costa magrebí o el embarque directo hacia países musulmanes, obligaron al gobierno español a idear nuevos itinerarios para la expulsión. Éstos fueron por la vecina Francia o por algunos estados italianos. En Francia reinaba aún Enrique IV, el de Navarra, que había tenido tratos con los moriscos en su política anti-española, y en Italia el soberano de Toscana planificaba enriquecerse con las inversiones económicas de algunos ricos 
moriscos y con una mano de obra barata para disecar y transformar en ricos territorios agrícolas diversas zonas pantanosas del país.

El camino de Francia para ir a territorios musulmanes está documentado por algunos itinerarios de viaje de los moriscos, a lo largo del XVI, que han llegado hasta nosotros. Algunos moriscos hasta se habían instalado en puertos franceses y ayudaron a los moriscos expulsados a embarcarse hacia otras tierras, como lo habían hecho con casos más individuales, antes de la expulsión.

Porque la inserción de los moriscos en la sociedad francesa resultó muy difícil y sólo se logró en muy contados casos y con precariedad ${ }^{28}$. Pronto se vio que Francia, al igual que Venecia y Toscana, resultaron ser un mero tránsito para miles de moriscos, que luego se embarcaban hacia Marruecos o hacia los territorios magrebíes, balcánicos o anatólicos del Imperio otomano.

\subsection{Marruecos: la capital Marrakech y las ciudades costeras de Tetuán y Salé-Rabat}

La capacidad de acogida del territorio y de la sociedad marroquíes fue muy importante, pero se canalizó por las estructuras urbanas tradicionales del sultanato, sumido políticamente en una importante guerra civil.

La capital Marrakech, al sur, al pie del Atlas y no lejos del desierto sahariano, había recibido durante siglos a inmigrantes de Al-Ándalus. Con la dinastía saadí había integrado a lo largo del siglo XVI numerosos moriscos, como los cuerpos de ejército ya mencionados o al conocido escritor bilingüe y diplomático granadino Áhmad Al-Háchari Bejarano $^{29}$. Los inmigrantes solían desembarcar en los puertos portugueses de la costa atlántica, que mantenían relaciones con la capital. No se sabe bien si utilizaron ese itinerario parte de los miles de inmigrantes moriscos de la gran expulsión, dada la situación política caótica de la capital, en aquellos años.

En cambio está muy bien documentada la llamada «república morisca de Salé-Rabat», que ocupó durante varias décadas esa zona estratégica costera de la desembocadura del río Bu-Regrag, dirigida políticamente por un grupo de moriscos, emprendedores comerciantes, ori-

La política de los moriscos con Francia y su travesía por el país, cuando la gran expulsión final, han sido estudiadas por L. Cardaillac, G. Turbet-Delof y otros, con escasa pero muy interesante documentación (ver en particular capítulos de L. Cardaillac y de M. de Epalza, en Receuil d'études..., pp. 89-113 y 150-186, respectivamente)

29 Ver estudio de C. Sarnelli, en Receuil d'études..., pp. 348-257; edición completa y estudio de su relato de viaje autobiográfico en árabe, por M. Razuq (Casablanca, 1987); y otros estudios de J. Penella, C. Sarnelli y G. Wiegers. 
ginarios de la población extremeña de Hornachos, ya especializada en España en el trajineo comercial. El comercio de los saletinos se realizaba sobre todo por mar, con una compleja diplomacia, que intentaba contrarrestar la continua presión de los jefes locales de la región y la de los soberanos marroquíes, que acabaron sometiendo a la ciudad, superadas las guerras civiles ${ }^{30}$.

Al norte, la ciudad de Tetuán y sus alrededores prosiguieron con su acción de acogida de musulmanes peninsulares, que había iniciado AlMándari, un siglo antes.

Entre Tetuán y Salé, un jefe militar de origen andalusí, Gailán, mantuvo durante décadas una lucha continua contra los portugueses y los españoles que ocupaban diversos puntos costeros. Contaba con tropas moriscas y tenía que defenderse también de la población local y de los moriscos de Tetuán y de Salé, a los que procuraba esquilmar para la subsistencia de sus seguidores.

Esta situación volvió a la administración más o menos directa del sultanato de Marrakech al asumir efectivamente el poder la nueva dinastía de chorfas, a mediados del siglo. Pero la situación de autonomía periférica, con gran peso de andalusíes en toda la costa noroccidental del reino, ayudó a muchos moriscos a integrarse en la sociedad del sultanato magrebí, donde se asimilaron totalmente, aunque guardaran algunas características hispánicas, que a veces se han conservado hasta nuestros días, debido también a los continuos flujos de la vecindad geográfica con España.

\subsection{El Imperio Otomano: Argel, Túnez, Trípoli, Egipto y el Máshrek, Estambul, Balkanes y Anatolia}

El Imperio Otomano, nacido en la península de Anatolia, resurgió con tanta fuerza de la gran crisis general de Oriente Medio producida por los mongoles de Tamerlán, a principios del siglo $\mathrm{XV}$, que no sólo conquistó la mítica Bizancio / Constantinopla / Estambul (1453), sino que a principios del siglo XVI se había hecho con la soberanía de casi todo el mundo árabe (menos Marruecos), desde Argelia hasta la Península de Arabia y el Irak. A lo largo de todo el siglo XVI, apoyó decisivamente a los moriscos musulmanes de España, especialmente desde su provincia (vilayet) de Argelia, aunque su eficacia no correspondiera a las esperanzas de triunfo sobre los españoles, que habían puesto en ellos los moriscos.

Ver documentada obra de conjunto, a partir de su tesis doctoral, de G. Gozálvez Busto, «La república andaluza de Rabat en el siglo XVII», Cuadernos de la Biblioteca Española de Tetuán, Tetuán, 9-10, 1974, 7-469, y volumen en árabe de M. Razuq sobre las emigraciones de los moriscos, Casablanca, 1989. 
No se puede uno extender, en la brevedad de este artículo, en las estructuras de acogida del Imperio Otomano con respecto a los moriscos ${ }^{31}$, ni a los numerosos estudios monográficos realizados sobre la insersión de los moriscos en Argelia ${ }^{32}$ y sobre todo en Tunisia ${ }^{33}$, Libia $^{34}$, Egipto ${ }^{35}$ y Anatolia ${ }^{36}$. Pero sí pueden señalarse dos características generales que caracterizan al gobierno otomano en su política de acogida de los inmigrantes moriscos expulsados de España.

Primero, que hubo una política general del Imperio Otomano sobre esa insersión, desde el Mágreb a Anatolia y los Balkanes, coordinada eficazmente desde la Sublime Puerta de Estambul, como lo ha mostrado Abdelmajid Temimi con docuentación otomana.

Segundo, que esa política estaba basada en su experiencia oriental de gobernar a los diferentes grupos étnicos o religiosos dejándoles que tuvieran sus propios jefes -supeditados a las autoridades otomanas de cada provincia.

Así tuvieron los andalusíes sus «sheij» en Túnez, al menos en Túnez y Trípoli ${ }^{37}$, y su «emir sanchak» en las implantaciones moriscas en Anatolia, tanto en las costas de Cilicia como en las fronteras con los persas $^{38}$. Pero esta institución o autonomía administrativa, como «minoría», no prosperó, ni en el Mágreb, ni en Oriente: en el Mágreb, por la falta de tradición de esta forma de grupo político (con excepción de los judíos y cristianos autóctonos, éstos sólo en la Alta Edad Media); en el resto del Imperio Otomano, seguramente por el escaso número de inmigrantes de origen hispano.

31 Ver M. de Epalza, «Les Ottomans et l'insertion au Maghreb des Andalous expulsés d'Espagne au XVIIe siècle», Revue d'Histoire Maghrébine, Túnez, 31-32- 1983, 165-173; trabajos de A. Temimi y artículos sobre la esperanza morisca en los turcos de L. Cardaillac y M. Sánchez.

32 Ver N. As-Sa'îdûnî, «La colonia andalusí en Argelia: su importancia demográfica, actividad económica, situación social», Awrâq, Madrid, 4, 1981, 111-124, 234 (en árabe, con resumen en castellano), y artículo antes citado.

33 Síntesis en M. de Epalza, Los moriscos antes y después..., 205-259; conjuntos de monografías en M. de Epalza; R. Petit (edits.), o.c. y S.M. Zbiss..., o.c.

34 Ver reciente monografía de E. Lapiedra, «Los moriscos en Libia», L'expulsió dels moriscos..., 369-371.

35 Ver A. A. Abdel-Rahim, «Al-Moriscos Settlement in Egypt through the Religious Court Documents of The Ottoman Age», en L'expulsió dels moriscos..., 158-163.

36 Ver A. Temimi, «Politique Ottomane face à l'implanatation et à l'insertion des Morisques en Anatolie», en L'expulsió dels moriscos..., 164-170.

37 Ver datos en M. de Epalza, «Moriscos y andalusíes en Túnez en el siglo XVII», Al-Andalus, Madrid, 34, 1969, 284-293, con versión en francés M. de Epalza; R. Petit, o.c., 175-181,

38 Ver A. Temimi, o.c. Tengo un pequeño estudio, a partir de los documentos publicados por Temimi, que muestra el doble carácter de las colonias moriscas según la política otomana, evidentes en el caso de Anatolia: son colonias agrícolas alrededor de las ciudades y son colonias en zonas militares de frontera, terrestre o marítima. Tendría que salir publicado en la revista Sharq Al-Ándalus. Estudios Mudéjares y Moriscos, Teruel, 13, 1996. 
Pero sobre todo dominó el deseo de los moriscos de integrarse en las sociedades de acogida, como creyentes musulmanes y como árabehablantes, prescindiendo cada vez más de los demás rasgos hispanos, limitados a la conciencia de origen y a algunos rasgos hispanos de esa tradición ${ }^{39}$.

\subsection{Resumen de la insersión de los emigrantes moriscos, por un con- temporáneo}

Un escritor argelino contemporáneo de la gran expulsión, AlMaqqari de Tremecén, al final de su monumental historia de los musulmanes de Al-Ándalus, describe la implantación de los moriscos expulsados en unas pocas líneas, de inmenso valor sintético: «Salieron millares para $\mathrm{Fez}$ [Marruecos] y otros millares para Tremecén [Argelia], a partir de Orán, y masas de ellos para Túnez [Tunisia]. En sus itinerarios terrestres, se apoderaron de ellos beduinos y gente que no teme a Dios, en tierras de Tremecén y Fez; les quitaron sus riquezas y pocos se vieron libres de estos males; en cambio los que fueron hacia Túnez y sus alrededores, llegaron casi todos sanos.

Ellos construyeron pueblos y poblaciones en sus territorios deshabitados; lo mismo hicieron en Tetuán, Salé y La Mitidja de Argel.

Entonces el sultán de Marruecos tomó a algunos de ellos como soldados armados. Se asentaron también en Salé. Otros se dedicaron al noble oficio de la guerra en el mar, siendo muy famosos ahora en defensa del Islam. Fortificaron el castillo de Salé y allí construyeron palacios, baños y casas, y allí están ahora.

Un grupo llegó a Estambul, a Egipto y a la Gran Siria, así como a otras regiones musulmanas. Actualmente así están los andalusies ${ }^{40}$

\subsection{Los últimos emigrantes moriscos al Mágreb (siglo XVIII)}

Parecía que con la gran «limpieza étnica» de la expulsión de los moriscos de España, en 1609-1614, se había terminado el dilatado período de estancia de musulmanes de la Península Ibérica y en la Península Ibérica: nueve siglos (711-1614). Algunos historiadores (L. Cardaillac, M. García-Arenal, B. Vincent) han encontrado algunos documentos, principalmente inquisitoriales, en el que aparecen algunos moriscos en las décadas que siguieron a la gran expulsión, especialmente de moriscos exiliados que vuelven a España o son captura-

39 Ver M. de Epalza, «Léxico y onomástica hispánicos de los moriscos, conservados en Tunisia», ponencia del VII Simposio de Estudios Mudéjares (Teruel, 1996), en prensa.

40 Traducción con comentario en M. de Epalza, Los moriscos antes y después..., p. 148. 
dos en la mar y juzgados como apóstatas -curiosa lógica de la actitud inquisitorial, con bautizados forzosos que habían sido expulsados precisamente por no ser cristianos, sino musulmanes inconvertibles-, últimos emigrantes de ida y vuelta, en un azaroso Mediterráne $o^{4 !}$.

A partir de esa época (hacia 1640, según Cardaillac ${ }^{42}$ ), ya sólo habría en España musulmanes esclavos, «prisioneros de guerra», hasta la supresión generalizada de la esclavitud en el siglo XIX ${ }^{43}$, viajeros (comerciantes y diplomáticos) y musulmanes españoles o establecidos en España modernamente, amparados por la libertad religiosa reconocida por los artículos 16 y 27 de la Constitución Española de 1978, por La Ley Orgánica de Libertad Religiosa (B.O.E. 20-07-1980) y específicamente por la Real Orden de 10 de noviembre de 1992, que reconoce el Acuerdo de Cooperación del Estado con la Comisión islámica de España (B.O.E. 12-11-1992), recientemente ampliado por lo que se refiere a los programas de religión musulmana de la enseñanza pública no universitaria (B.O.E. 18-01-1996) ${ }^{44}$. Esta misma legislación, al preservar la privacidad de la fe religiosa en el ordenamiento jurídico y administrativo español, no permite saber el número de musulmanes españoles y sólo aproximadamente el de los extranjeros, si son originarios de países de población mayoritariamente musulmana ${ }^{45}$

Pero un curioso episodio en el primer tercio del siglo XVIII (entre 1727 y 1732) va a renovar la situación de unos cripto-musulmanes, que se habían mantenido en secreto en la sociedad española granadi-

41 Ver reciente publicación de B. Vincent, «Et quelques voix de plus: de Francisco Núñez Muley à Fatima Ratal», Sharq Al-Ándalus. Estudios Mudéjares y Moriscos, Teruel, 12, 1995, en prensa.

42 Ver L. CARDAILLAC, Moriscos y Cristianos: un enfrentamiento polémico (1492-1640), Madrid, 1979.

43 Ver su supresión, al menos en lo referente a los marroquíes y de posesión estatal, con los reales acuerdos entre Carlos III y Sidi Muhámmad Ben-Abdallah, a fines del siglo XVIII, estudiados minuciosamente por R. Lourido y por M. Arribas Paláu, en un proceso político global de pacificación entre España y los países musulmanes, presentado por M. de Epalza, «Intereses árabes e intereses españoles en las paces hispano musulmanas del XVIII», Anales de Historia Contemporánea, Murcia, 1, 1982, 7-17.

44 Ver presentación general de la problemática en M. Abumalham (edit.), Comunidades islámicas en Europa, Madrid, 1995. Recientemente, J. MORERAS, «Les Accords de Coopération entre l'État Espagnol et la Commission Islamique d'Espagne», Revue Européenne des Migrations Internationales, 12/1, 1996, 77-89.

45. Sobre los musulmanes españoles, la bibliografía es escasa: ver A. Abumálham (edit.), o.c. [especialmente capitulos de Losada, Tatary y Valencia]; M. de Epalza (dir.), L'Islam d'avui... [especialmente capítulo de Epalza y Moreras]; F. López Barrios; M. J. Haguerty, Murieron para vivir. El resurgimiento del Islam y el Sufismo en España, Barcelona, 1983; y reciente encuesta de T. Roland-Gosselin, Convertis à l'Islam. Aujourd'hui, à Séville, Paris (Fondation pour le progrès de l'homme, vol. 73), 1995 (con prólogo de M. de Epalza, «Situations de «conversion» socioreligieuse dans les sociétés ibériques (Ve-XXe s.)», pp.5-13, 12I-122. 
$\mathrm{na}^{46}$. Descubiertos, por denuncias mutuas ante la Inquisición, se ven juzgados con bastante lenidad por unos tribunales inquisitoriales que hasta redactan un compendio de sus creencias islámicas, muy estructuradas con creencias cristianas compatibles con el Islam, para poder juzgarlos ${ }^{47}$. Integrados en su mayoría en la sociedad cristiana, con penas bastante leves, algunos de sus jefes fueron expulsados de Granada y se fugaron hacia la sociedad musulmana del Imperio Otomano (primero a Esmirna, importante puerto al oeste de Anatolia, y finalmente a Túnez, donde aún hoy en día sus descendientes forman parte de una gran familia burguesa de la capital, que hasta dio un primer ministro del Bey, en los años cuarenta ${ }^{48}$.

El texto del diario del director del hospital español de Túnez, Francisco Ximénez, en el que se nos informa de la llegada de esos granadinos es muy significativo de su insersión en la sociedad musulmana. A fecha de 27 de julio de 1731, dice: «Ha escrito desde Esmirna a Cherife Castelli un cierto Moza La Joa que dice ser descendiente de los Albencerrajes, natural de Granada, alcaide de la torre del Aceitunero y puerta de Taxalanza, el cual fue por la Inquisición de Granada castigado por morisco a cuatro años de destierro y se ha pasado con sus hermanos y hermanas a Esmirna. De allí /p,214/ pretende venir a vivir a esta ciudad. Habrá cuatro años que fue castigado ${ }^{49}$.

El nombre árabe del jefe de este grupo de inmigrantes permite hacer el lazo entre los granadinos y sus actuales descendientes tunecinos: Muza [Musa, Moisés] La Joa [«al-ijwa», actualmente escrito en francés Lakhoua, que significa «los hermanos», precisamente «sus hermanos y hermanas» del texto español, que les quedó como apellido]. Pero el texto de Francisco Ximénez añade más: informa que los granadinos refugiados en el Imperio Otomano se dirigen a Cherife Castelli, gran personalidad andalusí descendiente de los moriscos inmigrantes del XVII, riquísimo comerciante y hermano del Jaznadar o ministro de finanzas del Bey o gobernador de la provincia o regencia muy autónoma de Túnez; de ambos habla extensamente Ximénez en su diario.

46 Ver presentación general, bien documentada, de Rafael de Lera García, «Cripto-Musulmanes ante la Inquisición granadina en el s. XVIII», Hispania Sacra, Madrid, XXXVI, 1984, 1-55, así como en su tesis doctoral aún inédita.

47 Ver este curiosísimo texto, cuya lógica interna no ha sido aún suficientemente estudiada, en M.S. Carrasco Urgoiti; M. de Epalza, «El manuscrito «Errores de los moriscos de Granada» (Un núcleo criptomusulmán del siglo XVIII)», Fontes Rerum Balearum, Palma de Mallorca, III, 1979-1980, 235-247.

48 Ver M. de EPALZA, «Nuevos documentos sobre descendientes de moriscos en Túnez en el siglo XVIII», Studia historica et philologica in honorem M. Batllori, Roma, 1984, 195-228, especialmente pp. 213-4.

44 Ver nota precedente. 
Por tanto, aquí también, los emigrantes musulmanes de la Península se insertan en el Mágreb árabe gracias a la fraternidad de los andalusíes que les precedieron. Éstos lo hacen además con una solidaridad de clase, entre burgueses adinerados. Los granadinos expulsados eran emigrantes que pudieron salir con fuertes sumas de dinero, no sabemos cómo o por qué. Pero traían dinero, que invirtieron en una importante artesanía pre-industrial, la fabricación del «bonete tunecino» 0 «chechía», que era casi monopolio estatal llevado por los andalusíes del país, donde los Lakhoua llegaron a ser dirigentes, en el siglo XIX ${ }^{51}$. El dinero fue un poderoso factor positivo de insersión para estos granadinos, como lo había sido ya antes, para los moriscos o los andalusíes en general ${ }^{5 !}$.

La conclusión de este episodio tardío de las emigraciones de musulmanes moriscos españoles permite una conclusión final: aunque las estructuras de acogida fueran generales y variadas, la actuación individual y la suerte diversa condicionaron también los resultados de la insersión, con más peso a veces que las estructuras de acogida de la sociedad receptora. Parece que es ley general de todas las emigraciones.

\title{
APÉNDICE : \\ REFLEXIONES SOBRE LA INSERSIÓN SOCIAL DE LOS ESPA- ÑOLES EN EL MÁGREB A PARTIR DE LA BAJA EDAD MEDIA
}

\begin{abstract}
Este texto se presentó en Barcelona en 1975 y se publicó en las actas del II Congreso Internacional de Estudios sobre las Culturas del Mediterráneo Occidental, Barcelona, 1978, 161-165. Por la naturaleza y circunstancias de ese encuentro, en las tensiones internacionales y locales provocadas por la inminente muerte de Franco y sus sangrientos antecedentes, puede considerarse este texto como prácticamente inédito. Agradezco la ocasión que me permite publicarlo, con su vigencia y carácter autobiográfico, por mi experiencia de emigrante laboral español en el Mágreb, entre 1971 y 1974, en las universidades de Túnez, Argel y Orán.
\end{abstract}

En este Congreso consagrado a las emigraciones mediterráneas no es inútil estudiar las estructuras de acogida que tienen las sociedades a

so Ver $\mathrm{P}$. Teyssier, «Le vocabulaire d'origine espagnole dans l'industrie tunisienne de la chéchia», Mélanges offerts à Marcel Bataillon par les hispanistes français, Bulletin Hispanique, Bordeaux, LXIV bis, 1962, 732-740, reproducido en M. de Epalza; R. Petit, o.c., 308-316.

51 Ver D. Brahimi, «Quelques jugements sur les Maures Andalous dans les régences turques au XVIIe siècle», Revue d'histoire et de la civilisation du Maghreb, Argel, 9, 1970, 39-51, reproducido en M. de Epalza; R. Petit, o.p., 135-149, y M. de Epalza, «Moriscos y andalusíes en Túnez en el siglo XVII», Al-Andalus, Madrid, XXVIII, 1969, 247-327, traducido en M. de Epalza; R. Petit, o.c., 150-186. 
donde van a parar los emigrantes. Esta comunicación, limitada al Mágreb islámico desde la baja Edad Media, pretende ser una reflexión que llega hasta la época moderna, a partir de datos conocidos y sin tener que exponer una bibliografía muy extensa y también muy conocida.

La sociedad musulmana en general tiene unas estructuras de integración generales, según las categorías de personas, desde el creyente musulmán, teóricamente en plenitud igualitaria de derechos, hasta el infiel politeísta o idólatra o el renegado, carentes absolutamente de derechos. Además, existen en la socidad musulmana otras categorías públicas, reconocidas más o menos por la sociedad y hasta a veces por la religión y el derecho: califa, experto en religión, ricos y pobres, hombres y mujeres, profesiones diversas, niños y ancianos, etc. A cada categoría de personas corresponde una forma de inserción social o de asimilación, que repercuten en la integración de los emigrantes.

Aquí vamos a estudiar: $1^{\circ}$ la situación general de las inserciones de españoles o extranjeros en el Mágreb islámico, y $2^{\circ}$ preguntarnos en particular por la acogida de una categoría especial de extranjeros, que siempre ha sido difícil de situar socialmente por parte de los historiadores: los convertidos al Islam o «renegados», extranjeros que quieren vivir en el Mágreb con plenitud de derechos (profesionales, cívicos, familiares...).

\section{Esquemática descripción de los grupos de emigrantes en la Edad Media}

Hay que empezar tomando como base de acogida la situación de la sociedad magrebí, es decir, la sociedad de los musulmanes árabes, ya que el elemento beréber no tiene, en general, más estructuras de inserción del extranjero que las que le proporciona una sociedad de estado según el modelo árabe-islámico. Se conoce algún caso de pacto entre españoles y tribus beréberes, pero ninguno de asimilación de europeos a la sociedad beréber, por lo menos en la Edad Media, a no ser que haya tomado el poder de un estado árabe-islámico.

El problema socio-lingüístico beréber surge también con un elemento étnico de origen hispánico, emigrado al Mágreb, el de los moriscos o andalusíes, de los siglos XVI-XVII. Sus costumbres diferentes y su desconocimiento casi general de la lengua árabe hicieron que formaran un grupo aparte que tardó un poco en asimilarse. Pero cuando aprendieron la lengua pasaron a formar un sub-grupo de la sociedad árabe-islámica del Mágreb, en la que sólo se distinguían por su origen, Al-Ándalus, es decir, un territorio del mismo mundo árabe e islámico para la conciencia magrebí. Aquí el factor religioso común 
contribuyó decisivamente a su rápida y completa integración en el Mágreb.

Otros súbditos magrebíes que se integran de forma especial en la sociedad árab-islámica del Mágreb son los judios. Aquí el factor de diferenciación no es sobre todo el lingüístico, sino precisamente el religioso. Como todos los «protegidos» (cristianos y judíos), pagan con cierta discriminación social el precio de la conservación especial de su fe y de sus tradiciones pre-islámicas, al interior de la sociedad árabemusulmana. Están integrados en ella, pero de forma diferente a la de los musulmanes. Los judíos de origen español se fueron integrando al grupo de los judíos magrebíes, súbditos de los Estados musulmanes. Pero más adelante vinieron como súbditos italianos y hasta españoles, con estatuto de extranjero no asimilados.

Como extranjeros asimilados pueden considerarse los que abrazan la religión musulmana, llamados convertidos o renegados, según como se mire. El factor religioso ya no consituye un elemento que impida su integración en la sociedad musulmana y hasta el ejercer funciones técnicas y políticas importantes en ella. Con todo, quedan siempre -ellos y a veces sus sucesores- en el grupo de los «conversos» («ilch») de fe movediza. El estatuto pleno de musulmán les viene reconocido en principio, con precedentes gloriosos en tiempos del Profeta Mahoma. Hay muchos españoles en este caso en el Mágreb, ya desde la Edad Media.

Dentro de la categoría de los extranjeros asimilados están las mujeres no musulmanas esposas de musulman. Si se convierten al Islam, entran en la situación general de los convertidos. Pero la religión musulmana prevé que puedan conservar su fe, aunque no la puedan trasmitir a sus descendientes que, hijos de musulmán, seguirán la religión de su padre. En los casos que conocemos de españolas casadas con musulmanes en el Mágreb, pocas eran las que conservaron su religión, hasta tiempos muy recientes.

El caso de extranjero no musulmán que se casa con una musulmana está expresamente prohibido en el Islam. Por eso no puede ser un camino de integración, sino de rechazo por parte de la sociedad islámica.

Hay otros extranjeros que no se asimilan en la sociedad islámica, pero que conviven con ella. Son los extranjeros establecidos al amparo de tratados o capitulaciones, o como viajeros protegidos por las autoridades musulmanas y las representaciones «diplomáticas» aceptadas por ellas. Esta forma de presencia hispánica en el Mágreb tuvo pecisamente su época cumbre en la baja Edad Media. Comprendía a militares al servicio de los soberanos y algunos otros «técnicos», que a veces abrazaban el Islam para poder ejercer mejor su oficio y gozar de más influencia y derechos cívicos; comerciantes, más o menos estables; eclesiásticos, al servicio de la comunidad cristiana o encargados de hospitales y rescates de esclavos; los propios «diplomáticos» que 
eran también comerciantes y representaban al país y defendían a sus súbditos y sus intereses.

Finalmente hay unos extranjeros no asimilables por la sociedad islámica magrebí: los infieles politeístas o idólatras, en general; los musulmanes que reniegan de su religión; y los enemigos del Islam que hacen la guerra a los países musulmanes. Las dos primeras categorías apenas afectan a los españoles aunque se aplique a menudo a los cristianos el título de politeísta trinitario y que haya algún caso de magrebí musulmán bautizado en los territorios hispánicos. En cambio, todos los españoles vienen englobados en la categoría de enemigos del Islam que hay que combatir, sobre todo si ocupan territorios islámicos (AlẢndalus, Granada, plazas magrebíes). De ahí la constante y profunda inasimilación de las plazas o territorios ocupados por España en el Mágreb, aislados u hostigados por los musulmanes.

Una consecuencia de esta situación bélica lo constituye la situación del esclavo, botín de guerra del Mágreb, integrado a su manera en la sociedad magrebí. Tiene un estatuto intermediario entre el del politeísta enemigo del Islam (que habría que matar) y el del súbdito «protegido» (por ser cristiano), con algunos de los derechos de los extranjeros instalados (diplomáticos, comerciantes, eclesiásticos...) con los que mantiene múltiples relaciones.

Éstas son, esquemáticamente, las diversas categorías o formas de integración de los emigrantes extranjeros, particularmente españoles, en el Mágreb islámico. Al interior de cada grupo encontraríamos, evidentemente, nuevos subgrupos, según los lugares y las épocas.

\section{Pervivencias actuales de esas formas de integración en el Mágreb}

Estas formas de integración tradicionales del Mágreb islámico han sido profundamente modificadas en nuestros días, después del paréntesis colonial, bajo el impacto de la modernidad y de las nuevas relaciones internacionales. Pero presentan algunos caracteres de continuidad que merece le pena señalar. Vamos a ver, pues, qué queda de esas estructuras de acogida de emigrados hispánicos.

No hay emigraciones de musulmanes españoles. Los descendientes de los moriscos o andalusíes están perfectamente integrados en Mágreb árabe-islámico, aunque recuerden a menudo su origen hispánico.

La mayor parte de los judios protegidos por España, o bien se han acogido a la nacionalidad francesa (por ejemplo, en Túnez) o han emigrado a España o a sus territorios (por ejemplo, en Marruecos). De todas formas, su situación en el Mágreb no es ya tan discriminatoria como en la Edad Media y gozan en teoría de la igualdad de derechos 
cívicos con sus conciudadanos musulmanes, a pesar de las inevitables incidencias del conflicto palestino-israelí y el peso de la tradición popular discriminatoria.

Las mujeres no musulmanas esposas de musulmanes son más numerosas en la actualidad en conservar su religión. Guardan en general también la nacionalidad española, con lo que gozan de la mayor parte de los derechos de los extranjeros establecidos en el país.

El caso de un no-musulmán casado con una musulmana sigue siendo muy difícilmente asimilable en el Mágreb. Si se convierte al Islam, sigue un proceso de integración familiar y social que le va insertando cada vez más en el Mágreb islámico. Si no, el fenómeno de rechazo le obliga a volver a su país, con o sin su mujer.

El caso de los extranjeros establecidos, más o menos provisionalmente, en el Mágreb se ha extendido mucho y goza de múltiples garantías internancionales, concordes con la evolución de los tiempos, pero en la misma línea de convivencia no-asimilable en la Edad Media. Esta situación tiende a asemejarse a la instalación de todos los emigrantes de un país a otro, en el mundo. Son técnicos diversos -en quienes la conversión al Islam es rarísima-; eclesiásticos al servicio de las comunidades cristianas, en obras de beneficencia -sobre todo son religiosas femeninas- y en la enseñanza, que les convierte en realidad en técnicos; en empresa privadas o públicas españolas, que forman a veces equipos de de trabajo técnico, cuando se trata no sólo de vender productos, sino de vender fábricas u obras públicas, generalmente en cooperación hispano-magrebí; diplomáticos o servicios asimilados; etc.

Hay que notar que servicios medievales, como los apoyos militares, se hacen ahora a nivel más indirecto, en el marco diplomático o de organismos internacionales especializados y no enviando tropas. También el número de viajeros-turistas ha aumentado con las facilidades de desplazamiento.

Finalmente, los esclavos botín de guerra han desaparecido. La situación internacional de paz ha seguido a las guerras de ocupación colonial y de independencia. Los colonos, fruto de la situación política anterior, se han visto obligados a emigrar poco a poco, gracias a múltiples limitaciones que han ido imponiendo las leyes magrebíes, que excluyen prácticamente a los extranjeros de la propiedad inmobiliaria, sobre todo rural.

Después de este breve panorama que aclara los conceptos con el análisis de las situaciones, se puede uno preguntar mejor por la diferente inserción, en la Edad Media y en nuestros días, del extranjero que quiere gozar de plenitud de derechos en el Mágreb, especialmente si quiere trabajar allí como técnico con su competencia profesional. Es tema complejo, íntimamente ligado por una parte a la situación de falta de técnicos magrebíes que obliga a los diversos países magrebíes a 
instaurar una «cooperación técnica» con europeos después de la Independencia, y por otra parte, a la ya sensible situación de paro laboral que afecta ya a algunos sectores profesionales, empezando por la enseñanza.

Pero se puede resumir diciendo que el técnico extranjero en la Edad Media, para ejercer plenamente su trabajo y gozar de todos los derechos cívicos en el país, tenía que integrarse en la sociedad magrebí por la conversión al Islam. Esta condición no es necesaria actualmente, salvo para casarse con una musulmana. Eso indicaría que la estructura islámica tradicional se ha conservado más en el estatuto familiar que en la vida pública y profesional. Pero hay que reconocer que, respetando una serie de libertades que el extranjero tiene al igual que los magrebíes, el estatuto de extranjero que tiene el técnico se hace inasimilable en la sociedad magrebí y hace muy inestable su presencia en el Mágreb. Hasta su conversión al Islam, fuente de una casi total igualdad de derecho y de una integración social plena en la Edad Media, no le asegura actualmente una inserción permanente en el Mágreb con la concesión de la nacionalidad -naturalización-.

Se puede, pues, concluir diciendo que las emigraciones españolas en el Mágreb tienden a ser de una sola clase: la de los extranjeros en situación temporal, con plenitud de derechos, pero con insersión limi$\operatorname{tada}^{52}$.

52 Estas reflexiones sobre las estructuras magrebíes para recibir a españoles o hispanos peninsulares en general, a lo largo de siglos de historia, nacieron de mis personales estancias en el Mágreb, entre 1963 y 1974, de estudios históricos generales y experiencia de la realidad social magrebí, de mis estudios y publicaciones sobre los moriscos emigrados a Túnez y del estudio del más ilustre emigrante hispano en el Mágreb el franciscano mallorquín Anselm Turmeda, convertido al Islam a finales del siglo XIV, funcionario de los soberanos tunecinos y escritor en catalán y en árabe (con su nombre árabe de Abdállah At-Tarchumán), cuya tumba es un monumento en la capital, con una placa de las municipalidades de Túnez y de Palma de Mallorca. Fue objeto de mi tesis doctoral, defendida en la Universidad de Barcelona en 1967, publicada en Roma en 1971 y reeditada en Madrid en 1994: Fray Anselm Turmeda ('Abdallâh al-Taryumân) y su polémica islamo-cristiana. 